\title{
UM ESTUDO SOBRE A PRODUÇÃO NACIONAL DE SUCO DE LARANJA CONCENTRADO
}

\section{A STUDY ON NATIONAL PRODUCTION OF CONCETRATED ORANGE JUICE}

\author{
Fernando Samuel Feitoza - feitoza.fernando@outlook.com \\ Angelita Moutin Segoria Gasparotto - angelita.gasparotto@fatectq.edu.br \\ Faculdade de Tecnologia de Taquaritinga (Fatec) - Taquaritinga - São Paulo - Brasil
}

DOI: 10.31510/infa.v17i1.768

\section{RESUMO}

O presente trabalho se ocupa em traçar um panorama relacionado a aspecto pontuais referentes a citricultura nacional, visando compreender os produtos e subprodutos extraídos da laranja, uma fruta que torna atualmente o Brasil líder mundial de produção no ramo. $\mathrm{O}$ trabalho visa, também, realizar um estudo da produção de suco concentrado e os processos pelos quais passa esse produto. Onde através de pesquisas descritivas e exploratórias, pode-se constatar órgão que fiscalizam e regulamentarizam a qualidade do cultivo dessa fruta. $\mathrm{O}$ presente artigo busca uma valorização de citricultura nacional, tendo o papel essencial no desenvolvimento do país.

Palavras-chave: Citricultura. Cultivo de Laranja. Suco Concentrado. Modelo. Órgãos Fiscalizadores.

\begin{abstract}
This paper aims to draw a panorama related to specific aspects related to national citrus, aiming to understand the products and byproducts extracted from orange, a fruit that currently makes Brazil the world leader in the field. The work also aims to conduct a study of concentrated juice production and the processes through which this product goes. Where through descriptive and exploratory research, we can find agencies that oversee and regulate the quality of cultivation of this fruit. This article seeks an appreciation of national citriculture, playing an essential role in the development of the country.
\end{abstract}

Keywords: Citriculture. Orange cultivation. Juice Concentrate. Model. Regulatory agencies.

\section{INTRODUÇÃO}

Não é novidade que o Brasil seja um pais com uma cultura agrícola de produção, essa vocação para o ramo tornou o país uma grande produtor de uma variedade de matérias primas, 
que por sua vez são exportadas em enorme quantidades todos os anos e uma delas é a laranja, essa fruta torna o país campeão na citricultura mundial.

Segundo dados atualizados do website Brasil Agro (2019), o Brasil é o maior produtor mundial de laranja, seguido da china, União Europeia e Estados Unidos e afirma que nem de longe essa liderança pode ser retirada do país.

Neste artigo serão abordados assuntos relacionados a produção de laranja no Brasil, desde a história da citricultura no país, até as normas que regulamentarizam e os produtos produzidos a partir dessa matéria prima.

Neves et. al (2014), explana que o consumo de laranja e dos produtos extraídos dessa fruta é muito grande, sabendo que essa matéria prima pode ser vista em quase todas as residências nacionais e internacionais, sendo presentes também em padarias, restaurantes e supermercados, o autor afirma ainda que o povo brasileiro é responsável pelo consumo de quase $30 \%$ da produção nacional.

O objetivo geral dessa pesquisa é apresentar um estudo sobre a produção de suco de laranja concentrado no país, como também descrever cada uma das etapas do processo de fabricação e identificando assim os pontos fortes e fracos da produção nacional.

Por ser uma das matérias primas que movimentam a economia do país, realizar um estudo em torno da produção de laranja, se faz necessário. O estudo em torno desse tema visa salientar a importância da citricultura no Brasil.

\section{CITRICULTURA BRASILEIRA}

Segundo Neves et al. (2014) registros apontam que a laranja se originou no sul da Ásia, cerca de 4.000 anos, através das guerras e dos comércios entre países, levou em 1500 esses cítricos chegarem ao continente americano.

Neves et. al (2014) afirma também que o cultivo de laranja foi introduzido no Brasil logo no início de sua colonização, uma vez que o país permitia climas e terras propícias à uma boa vegetação, que se expandiu a todo território nacional.

Fernandes (2010) explana que em 1800 as várias plantações de laranja começaram a produzir uma variedade particular, que ficou conhecida como laranja Bahia ou laranja baiana, essa fruta surgiu em um dos pomares em Salvador e se propagou através de mudas enxertadas, que tomou a citricultura um ramo da agricultura Brasileira. 


\section{WTEERFAET TECNOLLGGCA}

A consolidação das indústrias de cítricos no Brasil se efetivou definitivamente no país após as frentes frias que ocorreram na Flórida entre as décadas de 70, 80 e 90, o que causou perdas significativas na produção norte americana, facilitando a exportação não só da laranja, mas, também, do suco brasileiro (ALCANTARA, 2017). A partir de então, a ausência de suco nesse país, provocada pela geada, transformou o Brasil em uma alternativa para os mercados norte-americano e europeu, surgindo pequenas fábricas no interior de São Paulo (HASSE, 1987).

A primeira fábrica de suco de laranja concentrado do Brasil foi a Companhia Mineira de Conservas, criada em 1962, no município de Bebedouro, SP (HASSE, 1987).

Atualmente o Brasil é líder na questão de citricultura, além de ainda ser o maior exportador de laranja do mundo, segundo o Instituto Brasileiro de Geografia e Estatística IBGE (2019) só em novembro a produção estimada foi de 17.720 .305 toneladas de laranja, e $30 \%$ de toda a produção é destinada ao próprio país.

\subsection{Normas regulamentadoras}

Segundo o Ministério da Agricultura, Pecuária e Abastecimento (MAPA, 2011), o Brasil se detém da vigente LEI $\mathrm{N}^{0}$ 10.711, que trata do Sistema Nacional de Mudas e Sementes, visando atender a qualidade e identidade do material de multiplicação e reprodução produzido e distribuído.

O país ainda não possuí normas que regulamentam especificamente a citricultura, entretanto o MAPA, tem a responsabilidade ambiental e judicial, de orientar e fiscalizar os esforços relacionados a citricultura Nacional.

Segundo MAPA (2011) dentre os marcos regulatórios, são de obrigatoriedade:

$$
\begin{aligned}
& \text { Revisar e adequar o trânsito de mudas e frutos. } \\
& \text { - Revisar e adequar definição de Padrões de Qualidade, } \\
& \text { Comercialização e Importação de frutas fresca, sucos e polpas. } \\
& \text { • Criar, sob o arcabouço dos macros regulatórios adequados e } \\
& \text { revisado um sistema de mudas de citrus. } \\
& \text { - Revisar as normas para permitir a atuação no Setor Privado em } \\
& \text { unidades de produção de material básico de multiplicação (Matrizes), além do poder } \\
& \text { do Estado e em diversas regiões do Brasil. (MAPA, 2011, p.17 e 18). }
\end{aligned}
$$

A legislação brasileira possui também o Decreto $n^{\circ} 6.871$, prescrito no dia 4 de Julho de 2009, que ordena a Lei 8.918, criada no dia 14 de Julho 1994, e que regulariza e padroniza, definindo a inspeção e fiscalização do suco concentrado como uma bebida não fermentada, 


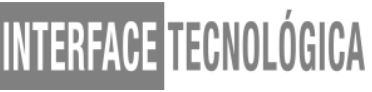

que necessita ser submetida a tratamentos que permitam a conservação da mesma até o consumo.

\subsection{Produtos produzidos através da laranja}

Segundo a Associação Nacional de Exportação de Sucos Cítricos (CITRUS BR, 2019a) o consumo da laranja in natura no Brasil é algo comum nas casas, entretanto nos outros países o que se consome mesmo é o suco extraído dessa fruta, podendo ser o fresco (espremido diretamente da fruta) ou o industrializado.

Segundo Laste, Hoss e Antoniazzi (2003) outros subprodutos podem ser aproveitados e exportados pelas indústrias brasileiras, alguns deles são:

- Citrus Base: esse produto é resultante da moagem da fruta inteira ou do suco concentrado com a casca da fruta moída e é utilizado como base para bebidas e refrigerantes a base de frutas.

- $\quad$ Polpa: são os gomos de suco rompidos ou o que resta após a extração do suco.

- $\quad$ Suco extraído da Polpa: obtido após a lavagem da polpa.

- Óleo de laranja: extraído da casca e pode ser utilizado em bebidas ou produtos químicos.

É fato que a laranja pode ser também utilizada até mesmo na produção de álcool, que é produzido através da prensagem do bagaço da fruta, que gera um líquido onde a fermentação dele resulta em álcool.

\section{PROCEDIMENTOS METODOLÓGICOS}

O presente trabalho possui caráter descritivo e exploratório, a fim de que se evidencie um assunto de extrema importância para o país, uma vez que, o país é líder na produção de cítricos no mundo todo, e a citricultura movimenta grande parte da economia nacional.

Para isso, foi traçado um panorama geral a respeito dos produtos e subprodutos produzidos através da laranja, com enfoque na produção de suco concentrado de laranja produzido pelas indústrias brasileiras, e por ser depois da fruta in natura o produto mais exportado. 


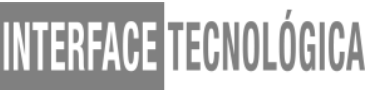

Segundo Gil (2006), o objetivo de uma pesquisa exploratória é compreender e familiarizar sobre o assunto, apesar da pouca disponibilidade de material.

\section{RESULTADOS E DISCUSSÃO}

Essa seção destina-se a apresentar os resultados da pesquisa descritiva e exploratória.

\subsection{Produção de suco de laranja concentrado}

Fernandes (2010) afirma que as empresas processadoras de suco de laranja surgiram na década de 60 , devido ao grande potencial e estrutura citrícola do país, onde cerca de $74 \%$ da produção de fruta e suco de laranja de todo o Brasil, está localizada no estado de São Paulo.

Segundo o website Investe São Paulo (2013) o estado conta com usinas processadoras de suco em mais de 20 municípios, onde $95 \%$ da produção é destinada à exportação e em sua maior parte para a Europa.

Ao analisar e compreender a estrutura econômica, é possível entender os pontos fortes que o estado de São Paulo possuiu, pois o mesmo se detém de oferta e demanda abundante e de qualidade, clima favorável para o cultivo da fruta, indústrias de grande escala com navios próprios e portos de armazéns particulares, entre outros.

Segundo o Portal do Agronegócio (2019) apesar dos brasileiros consumirem uma grande porcentagem da fruta in natura, a laranja é consumida principalmente em forma de suco.

A cada cinco copos de suco de laranja consumidos no mundo, três são produzidos nas fabricas brasileiras, em nenhuma outra commodity, o país tem amplitude semelhante (CITRUS BR, 2019b).

Segundo informações do Portal do Agronegócio (2019) o Brasil é responsável por cerca de $82 \%$ da exportação de suco, e só em 2018 os embarques de suco concentrado, congelado, para o exterior foram de 741.042 toneladas, que juntos somam o valor de R $\$ 1,3$ bilhão de reais. Entretanto, ao comparar a produção do ano de 2019, nota-se uma queda de exatamente $13 \%$, entre as safras. 


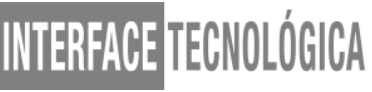

\subsection{Processo de produção do suco concentrado}

O processo produtivo do suco concentrado possuí algumas etapas nas quais são fundamentais para se obter qualidade no produto acabado, sendo também imprescindíveis no processo produtivo de qualquer empresa de suco de laranja.

Bueno et. al (2016), apontam 3 etapas, que necessitam uma atenção maior por parte dos produtores de laranja, sendo elas:

- Recebimento e armazenagem da matéria prima: essa fase é de extrema importância, pois o mal armazenamento da fruta pode trazer perdas significativas.

- $\quad$ Limpeza: prevista por lei a fase da limpeza é de fato importante, pois é nesses momentos em que possíveis bactérias são removidas (mesmo que não completamente).

- Seleção: nesse momento a atenção é crucial, pois nesta fase é realizada a inspeção visual, retirando assim toda a matéria prima que não serve, como por exemplo, frutas podres ou danificadas.

Segundo Bihre, Cirolini e Rutsatz (2003), além dessas etapas a matéria prima passa pelo processo de extração, filtração, pasteurização, concentração, resfriamento, embalagem e estocagem.

No processo de extração o objetivo é retirar o máximo de suco da laranja, através de uma prensa específica, que exerce uma pressão sob a fruta, restando apenas o bagaço e as sementes. A filtração tem a função de ajustar o teor final da polpa de suco, que tem uma variação entre $1 \%$ e $6 \%$ e é realizado normalmente através da centrifugação.

A partir disso o suco passa pela fase de pasteurização, para aplicação de calor para inativar ou destruir os micro-organismos presentes na fruta que degradam o suco de laranja, depois é encaminhado através de tubos para que seja feita a remoção da água através de evaporadores, o aquecimento do suco pode chegar até $103^{\circ} \mathrm{C}$, entretanto ao chegar na fase de resfriamento, o suco passa de $103^{\circ} \mathrm{C}$ a até $0^{\circ} \mathrm{C}$, o suco resfriado é encaminhado aos tanques de armazenamento nas câmaras frias podendo assim ser transportados através de tanques para serem embalados e estocados. 


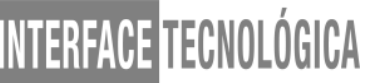

\subsection{Produção do suco concentrado no estado de São Paulo}

Segundo a Citrus BR (2019b) o estado de São Paulo é líder de toda a produção de laranja e suco concentrado dessa matéria prima no Brasil, onde SP corresponde a 53\% da produção mundial de laranja.

É fato que o Brasil caracteriza o mercado citrícola, como objeto de orgulho nacional, uma vez que esta área do agronegócio traz ao país liderança no mercado. Savenhago (2018) afirma que apesar do país possuir grandes empresas como Citrosuco, Louis Dreyfus e Cutrale, pequenas empresas estão surgindo no país, devido ao alto consumo e o crescimento de $10 \%$ a $12 \%$ ao ano.

Na ilustração 1 é possível identificar os estados de São Paulo e as grandes e pequenas empresas que estão ativas atualmente no mercado.

Ilustração 1 - Mapeamento do estado de São Paulo e as empresas de suco de laranja ativas.

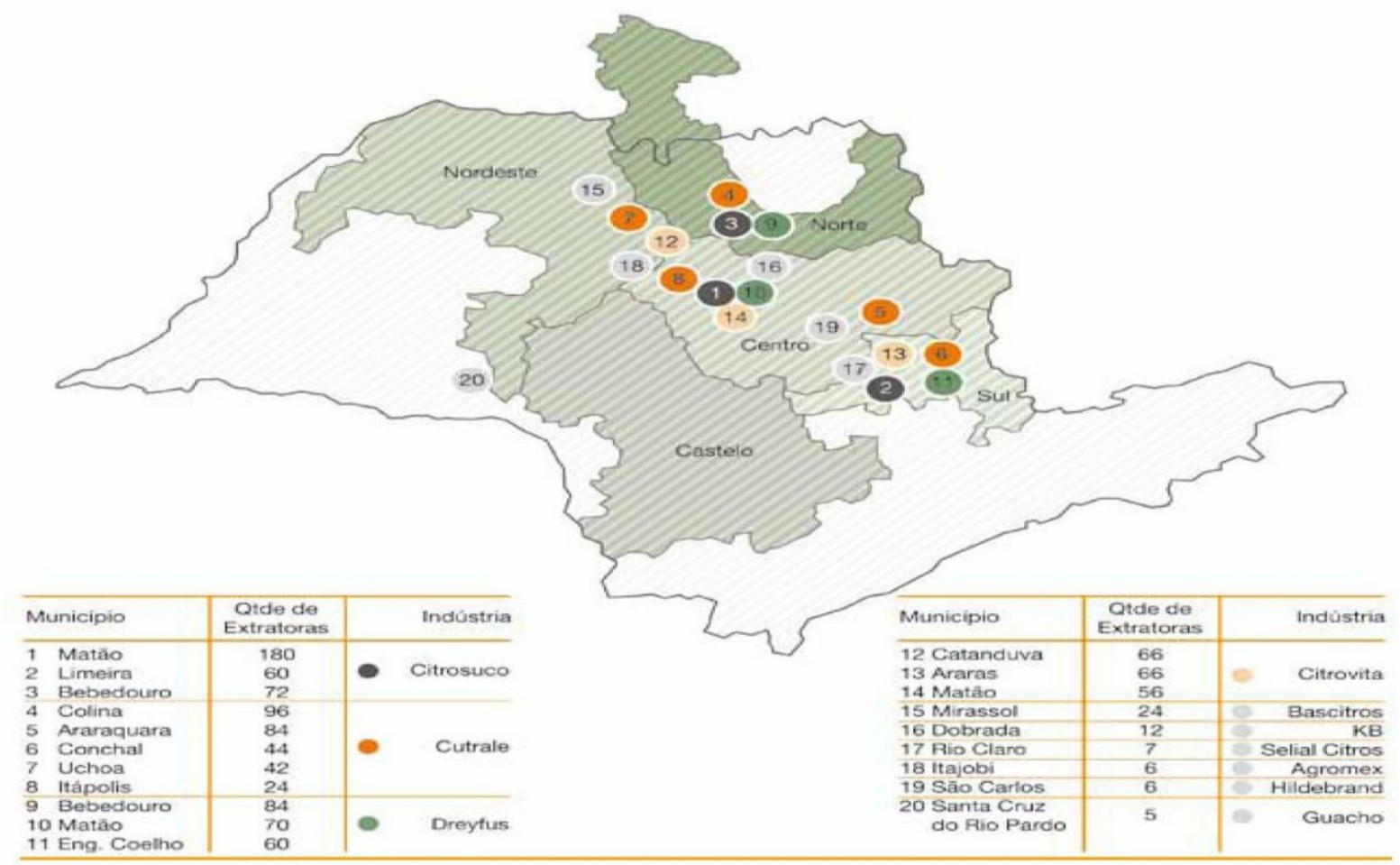

Fonte: Citrus BR (2019b)

Como é visível notar, apesar da Citrosuco possuir indústria em apenas 3 cidades, essa empresa possui grande quantidade de extratoras de laranja o que a mantém líder na produção. É possível analisar também que toda a região em torno da cidade de Taquaritinga, possui ao 


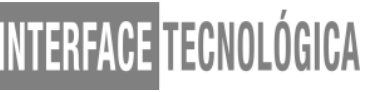

menos uma indústria do ramo, dentre as cidades podemos citar Matão, Dobrada, Araraquara e Itápolis.

Então, ao analisar a ilustração 1 e traçar um panorama anual de crescimento (12\%), é possível compreender que haverá um aumento não apenas no consumo, mas no número de empresas extratoras de laranja, fortalecendo e aumentando a economia do interior do estado de São Paulo.

\section{CONCLUSÃO}

O presente artigo objetivou pesquisar a produção nacional de suco laranja, e as etapas que o processo produtivo de suco concentrado possui, até estar pronto para ser consumido.

Ao estudar o tema pode-se constatar a eficiência do Brasil perante a citricultura, uma vez que o país é líder mundial na produção e exportação de laranja, além disso foi possível identificar que o estado de São Paulo possui em sua extensão as 3 maiores indústrias de suco de laranja, nacional e internacionalmente, além de ser o estado que mais cultiva e produz laranja no país.

Conclui-se que a citricultura possui uma viabilidade econômica positiva, desse modo o Brasil possui potencial superior em relação a outros países, além do mais é possível compreender que a produção de laranja em seu aumento contínuo pode beneficiar a região do interior de SP, pois a mesma torna o mercado mais aberto a oportunidades de investimentos.

\section{REFERÊNCIAS}

ALCÂNTARA, M. R. A Competitividade na produção de laranja. Orientador: Marco Tulio Ospina Patino. 2017. 98 f. Monografia (Graduação em Engenharia Agrícola) UNICAMP, CAMPINAS, 2017. Disponível em: http://repositorio.unicamp.br/bitstream/REPOSIP/325718/1/Alcantara_MillaReisDe_D.pdf. Acesso em: 10 dez. 2019.

BRASIL AGRO. Laranja:safra mundial cresce, oferta de suco avança mais do que a demanda. 2019. Disponível em: https://www.brasilagro.com.br/conteudo/laranja-saframundial-cresceoferta-de-suco-avanca-mais-do-que-a-demanda.htm. Acesso em: 03 dez. 2019

BIHRE, E.; CIROLINI, J.; RUTSATZ, M. Fluxograma do processo produtivo do suco concentrado. 2003. Disponível em: https://

http://www.ufrgs.br/alimentus1/feira/prfruta/slc/Processo/processo_base.htm. Acesso: 18 dez. 2019. 
BUENO, B. O. et. al. Produção de suco de laranja concentrado. 2016. 27 p. TCC (Ensino Técnico em Química) - Curitiba. Disponível em: http://www.ceepcuritiba.com.br/wpcontent/uploads/2019/05/Producao-de-suco-de-laranja-concentrado.pdf. Acesso em: 18 dez. 2019.

CITRUS BR. Laranja e Suco. [S. l.], 2019a. Disponível em: http://www.citrusbr.com/laranjaesuco/?ins=19. Acesso em: 10 dez. 2019.

Localização das Fábricas. [S. l.], 2019b. Disponível em:

http://www.citrusbr.com/economia/?ec=06. Acesso em: 10 dez. 2019.

FERNANDES, B. C. Desenvolvimento histórico da citricultura brasileira. Orientador: Sergio Gertel. 2010. 49 p. Monografia (Graduação em Ciências Econômicas) - UNESP, Araraquara, 2010. Disponível em:

https://repositorio.unesp.br/bitstream/handle/11449/118999/fernandes_bc_tcc_arafcl.pdf?sequ ence $=1 \&$ isAllowed $=\mathrm{y}$. Acesso em: $10 \mathrm{dez} .2019$.

GIL, A. C.; Como elaborar projetos de pesquisa. 4 ed. São Paulo: Atlas, 2006.

HASSE, Geraldo. A Laranja no Brasil. São Paulo: Duprat \& lobe, 1987.

INSTITUTO BRASILEIRO DE GEOGRAFIA E ESTATÍSTICA (IBGE). Produção estimada de laranja. 2019. Disponível em:

https://www.ibge.gov.br/busca.html?searchword=Laranja. Acesso em: 10 dez. 2019.

INVESTE SÃO PAULO. Laranja. 2013. Disponível em:

https://www.investe.sp.gov.br/uploads/midias/documentos/laranja_saopaulo.pdf. Acesso: 18 dez. 2019.

LASTE, G. D; HOSS, L; ANTONIAZZI, S. Principais produtos derivados da laranja. [S. l.]: Alimentus, 2003. Disponível em:

http://www.ufrgs.br/alimentus/afeira/produtos/frutas/suco-de-laranja-pasteurizado-1/materiaprima/principais-produtos-derivados-da-laranja. Acesso em: 10 dez. 2019.

MINISTÉRIO DA AGRICULTURA, PECUÁRIA E ABASTECIMENTO (MAPA). Agenda estratégica: Citricultura. Brasília: Assessoria de Comunicação Social, 2011. Disponível em: http://www.agricultura.gov.br/assuntos/camaras-setoriaistematicas/agendas/arquivos/citricultura.pdf. Acesso em: 10 dez. 2019.

NEVES, M. F. et al. O Retrato da Citricultura Brasileira. 1. ed. São Paulo: Markestrat, 2014. 138 p. Disponível em:

http://www.citrusbr.com/download/Retrato_Citricultura_Brasileira_MarcosFava.pdf. Acesso em: 10 dez. 2019.

PORTAL DO AGRONEGÓCIO. Brasil é o maior produtor e exportador de suco de laranja. 2019. Disponível em: https://www.portaldoagronegocio.com.br/noticia/brasil-e-omaior-produtor-e-exportador-de-suco-de-laranja-184243. Acesso em: 18 dez. 2019. 
SAVENHAGO, I. Alta do consumo de suco de laranja no Brasil impulsiona pequenas empresas em SP. G1, 2018. Disponível em: https://g1.globo.com/sp/ribeirao-pretofranca/estacao-agro/noticia/2018/11/30/alta-do-consumo-de-suco-de-laranja-no-brasilimpulsiona-pequenas-empresas-em-sp.ghtml. Acesso em 06 jan. 2019. 